http://dx.doi.org/10.32929/2446-8355.2020v29n1p76-91

\title{
COBERTURA DO SOLO, EVAPOTRANSPIRAÇÃO E PRODUTIVIDADE DO MILHO SAFRINHA
}

\author{
Joao Danilo Barbieri $^{{ }^{*}}$, Rivanildo Dallacort ${ }^{2}$, Diego Fernando Daniel ${ }^{3}$, Flávio Carlos \\ Dalchiavon $^{4}$, Paulo Sérgio Lourenço de Freitas ${ }^{5}$
}

\footnotetext{
${ }^{1}$ Doutorando em Agronomia, Universidade Estadual de Maringá - UEM, Maringá - PR. *E-mail do autor para correspondência: jd.barbieri@ hotmail.com

${ }^{2}$ Professor do Programa de Pós Graduação em Ambiente e Sistema de Produção Agrícola, Universidade do Estado de Mato Grosso - UNEMAT, Tangará da Serra - MT.

${ }^{3}$ Mestrando do Programa de Pós Graduação em Ambiente e Sistema de Produção Agrícola, Universidade do Estado de Mato Grosso - UNEMAT, Tangará da Serra - MT.

${ }^{4}$ Professor adjunto do departamento de Agronomia, Instituto Federal Tecnológico de Mato Grosso - IFMT, Campo Novo do Parecis - MT.

${ }^{5}$ Professor do Programa de Pós Graduação em Agronomia, Universidade Estadual de Maringá - UEM, Maringá - PR.
}

Recebido: 30/05/2019; Aceito: 27/03/2020

RESUMO: Objetivou-se avaliar a influência da cobertura do solo na evapotranspiração e nas características produtivas do milho safrinha na região de Tangará da Serra - MT. O experimento foi conduzido no campo experimental da UNEMAT, no ano de 2016, com três tratamentos e 28 repetições, sendo: sem cobertura vegetal; cobertura com $4 \mathrm{t} \mathrm{ha} \mathrm{a}^{-1} \mathrm{e}$ cobertura com $8 \mathrm{t} \mathrm{ha}^{-1}$ de massa seca de braquiária. A evapotranspiração da cultura do milho - ETc, foi determinada através de lisímetros de pesagem e a evaporação do solo foi determinada em microlisímetros. A ETc acumulada para o tratamento sem cobertura vegetal foi de 335,94 $\mathrm{mm}$; 304,60 mm com cobertura de $4 \mathrm{t} \mathrm{ha}^{-1}$ de braquiária e 332,05 $\mathrm{mm}$ com cobertura de $8 \mathrm{t} \mathrm{ha}^{-}$ ${ }^{1}$ de braquiária. A evaporação do solo foi reduzida em $68,64 \mathrm{~mm}$, quando utilizado cobertura de $4 \mathrm{t} \mathrm{ha}^{-1}$, em 74,74 mm quando utilizou-se $8 \mathrm{t} \mathrm{ha}^{-1}$. A transpiração aumentou 36,58 $\mathrm{mm} \mathrm{e}$, $69,65 \mathrm{~mm}$, respectivamente, em relação ao tratamento sem cobertura do solo. Todas as variáveis de características produtivas do milho foram influenciadas positivamente pelo uso de cobertura do solo. A produtividade foi de 8264,67; 9929,18 e 9939,52 $\mathrm{kg} \mathrm{ha}^{-1}$, para os tratamentos sem cobertura, com cobertura de $4 \mathrm{t} \mathrm{ha}^{-1}$ e $8 \mathrm{t} \mathrm{ha}^{-1}$, respectivamente.

Palavras-chave: Zea mays L. Evaporação do solo. Lisimetria. Microlisímetros. Transpiração da planta.

\section{SOIL COVERAGE, EVAPOTRANSPIRATION AND PRODUCTIVITY OF OFF- SEASON CORN}

\begin{abstract}
The objective of this study was to evaluate the influence of soil cover on evapotranspiration and the yield characteristics of the off-season corn crop in the Tangará da Serra - MT region. The experiment was conducted in the experimental field of the State University of Mato Grosso, in the year 2016, with 28 replications and three treatments, being: without vegetation cover; Cover with $4 \mathrm{tha}^{-1}$ of dry mass of brachiaria and cover with $8 \mathrm{tha} \mathrm{ha}^{-1}$
\end{abstract}


of dry mass of brachiaria. For the calculation of reference evapotranspiration - ETo, the Penman-Monteith methodology was used. The evapotranspiration of the corn - ETc crop was determined through six weighing lysimeters and soil evaporation was determined in microlysimeters. The ETc accumulated for the treatment without vegetal cover was of 335.94 $\mathrm{mm} ; 304.60 \mathrm{~mm}$ with cover of $4 \mathrm{t} \mathrm{ha}^{-1}$ of brachiaria and $332.05 \mathrm{~mm}$ with cover of $8 \mathrm{t} \mathrm{ha}^{-1}$ of brachiaria. Soil evaporation was reduced by $68.64 \mathrm{~mm}$ when using $4 \mathrm{t} \mathrm{ha}^{-1}$ cover, in $74.74 \mathrm{~mm}$ when using $8 \mathrm{t} \mathrm{ha}^{-1}$. The transpiration increased $36.58 \mathrm{~mm}$ and, $69.65 \mathrm{~mm}$, respectively. All variables of corn production characteristics were positively influenced by the use of soil cover. The productivity was $8264.67 ; 9929.18$ and $9939.52 \mathrm{~kg} \mathrm{ha}^{-1}$, for the treatments without cover, with coverage of $4 \mathrm{tha}^{-1}$ and $8 \mathrm{tha}^{-1}$, respectively.

Keywords: Zea mays L. Soil evaporation. Lisimetry. Microlysimeters. Plant transpiration.

\section{INTRODUÇÃO}

No Mato Grosso, principal produtor nacional de grãos, o plantio do milho safrinha atingiu pouco mais de 4,47 milhões de hectares na safra 2017/2018 (COMPANHIA NACIONAL DE ABASTECIMENTO - CONAB, 2019), sendo que a produtividade média para o estado foi de $5860,0 \mathrm{~kg} \mathrm{ha}^{-1}$. Com relação a anos anteriores houve uma redução da produção de milho devido ao custo de produção e as variações climáticas como baixas temperaturas, para regiões sul e sudeste do país, contudo essa redução da produção proporcionou aumento do custo de sementes e insumos para a cultura.

Em virtude da irregularidade na distribuição pluviométrica, bem como, a ocorrência de veranicos, o cultivo realizado na segunda safra no estado, possui alguns riscos quando a semeadura não é realizada nos primeiros decêndios do ano, principalmente, se houver déficit hídrico no período crítico da cultura, que compreende o $3^{\circ}$ e $5^{\circ}$ estádio vegetativo, e a fase de florescimento até o enchimento de grãos (DALLACORT et al., 2011; BARBIERI et al., 2015).

A água é fator crucial para o desenvolvimento da planta de milho, cujo déficit é um dos principais causadores de queda da produtividade (BARROS; CALADO, 2014). Logo, conhecer a dinâmica da água em cultivos de milho, pode contribuir para a adoção de estratégias de manejo que visem proporcionar maior eficiência no uso da água pela planta.

Nos cultivos agrícolas, a perda de água ocorre através do processo de evapotranspiração, onde há a ocorrência simultânea dos processos de transpiração da planta e evaporação do solo (SILVA et al., 2015b). Na transpiração, a planta perde a água em forma de vapor para a atmosfera (RHODEN et al., 2016), enquanto a evaporação é a remoção de água do solo para a atmosfera na forma vaporizada (SCHLESINGER; JASECHKO, 2014; RODRIGUES, 2017).

A evapotranspiração é uma das variáveis mais importantes no ciclo hidrológico, consistindo na ligação entre energia, clima e disponibilidade hídrica, podendo ser estimada por diferentes métodos, ou determinada em condições locais por meio de lisímetros, sendo este o mais indicado, devido às características intrínsecas de cada local (FARIA; 
CAMPECHE; CHIBANA, 2006; FENNER et al., 2019).

O objetivo deste estudo foi avaliar a influência da cobertura do solo na evapotranspiração e nas características produtivas do milho safrinha na região de Tangará da Serra - MT.

\section{MATERIAL E MÉTODOS}

O experimento foi realizado na área experimental da Universidade do Estado de Mato Grosso - UNEMAT, Campus de Tangará da Serra, no ano de 2016, no período de julho a novembro, nas dependências do Centro de Pesquisas, Estudos e Desenvolvimento Agroambientais - CEPEDA, no laboratório de Agrometeorologia e Horticultura. A região apresenta uma estação seca, de maio a setembro e uma chuvosa, de outubro a abril, com precipitação média anual de $1.830 \mathrm{~mm}$ e temperatura média anual de $26,1{ }^{\circ} \mathrm{C}$ (DALLACORT et al., 2011). O solo desta localidade é classificado como Latossolo Vermelho distroférrico, com textura muito argilosa (EMPRESA BRASILEIRA DE PESQUISA AGROPECUÁRIA EMBRAPA, 2013).

Próximo à área experimental, encontra-se instalada uma estação meteorológica automática modelo da Campbell Scientific, com coordenadas geográficas $14^{\circ} 65^{\prime} 00^{\prime \prime} \mathrm{S}, 57^{\circ}$ 43' 15" W com elevação de 440 metros, da qual foram obtidos os dados meteorológicos, como a temperatura, precipitação, a radiação solar, velocidade do vento, umidade relativa do ar e pressão atmosférica, utilizados para estimar a evapotranspiração de referência - ETo, método Penman-Monteith - Boletim FAO 56 (ALLEN et al., 1998).

Foram utilizados seis lisímetros de pesagem de alta precisão, com área de 2,25 $\mathrm{m}^{2}$ (1,50 $\mathrm{x} 1,50 \mathrm{~m})$ e $1,20 \mathrm{~m}$ de profundidade. Estes, foram previamente calibrados, conforme metodologia de Faria, Campeche e Chibana (2006) e utilizada por Fenner et al. (2019), com o objetivo de estabelecer a relação entre o sinal emitido pela célula de carga (mv) e a oscilação de massa do conjunto $(\mathrm{kg})$, que se dá por meio da evapotranspiração, irrigação, precipitação e drenagem. Os lisímetros foram identificados de um a seis, onde realizou-se sorteio para determinar quais desses receberiam cada tratamento.

O experimento foi implantado com semeadura manual nos seis lisímetros e, no mesmo dia foi realizada a semeadura de bordadura, totalizando $500 \mathrm{~m}^{2}$ de área experimental, com espaçamento entre linhas de 0,45 m. A cultivar utilizada foi a AG7088 RR, híbrido simples, de ciclo precoce, com população de 60.000 plantas por hectare.

A adubação e calagem do solo foram realizadas de acordo com os resultados da análise do solo (Tabela 1), tanto para o solo dos lisímetros, quanto para a bordadura em torno dos mesmos. A adubação de base constituiu de $45 \mathrm{~kg}$ de $\mathrm{K}_{2} \mathrm{O}$ e $95 \mathrm{~kg}$ de $\mathrm{P}_{2} \mathrm{O}_{5}$, aplicados na linha da semeadura. No total, aplicou-se $314 \mathrm{~kg}$ de $\mathrm{N}$, fonte ureia, sendo parcelado em três aplicações, uma na semeadura e duas aplicações de cobertura, uma quando a cultura estava no estádio V4 e outra no estádio V8 de desenvolvimento.

O delineamento experimental adotado foi o de blocos casualizados (DBC), com três tratamentos e 28 repetições, sendo estes: solo cultivado com milho sem cobertura, solo 
cultivado com milho com $4 \mathrm{t}^{-1}$ de braquiária e solo cultivado com milho com $8 \mathrm{t} \mathrm{ha}^{-1}$ de braquiária. A braquiária (Brachiaria brizantha cv. Paiaguás) foi coletada nas dependências da Universidade do Estado de Mato Grosso, campus de Tangará da Serra, mantida em estufa de circulação forçada de ar com temperatura de $65{ }^{\circ} \mathrm{C}$ até atingir peso de massa constante. A cobertura vegetal foi disposta uniformemente nos lisímetros 14 dias após a emergência da cultura.

Tabela 1. Características química do solo na profundidade de $0-20 \mathrm{~cm}$ dos lisímetros e da área experimental no entorno dos lisímetros (bordadura), na Universidade do Estado de Mato Grosso em Tangará da Serra - MT. Soil chemical characteristics in the depth of $0-20 \mathrm{~cm}$ of the lysimeters and the experimental area around the lysimeters (border), at the State University of Mato Grosso in Tangará da Serra - MT.

\begin{tabular}{|c|c|c|c|c|c|c|c|c|c|c|c|}
\hline \multirow{2}{*}{ Amostra } & \multicolumn{2}{|c|}{$\mathrm{pH}$} & $\mathrm{P}$ & $\mathrm{K}$ & $\mathrm{Ca}$ & $\mathrm{Mg}$ & $\mathrm{Al}$ & $\mathrm{H}$ & CTC & \multirow{2}{*}{$\begin{array}{l}\mathrm{V} \\
\%\end{array}$} & \multirow{2}{*}{$\begin{array}{r}\text { M.O } \\
\mathrm{g} \mathrm{dm}^{-3}\end{array}$} \\
\hline & $\mathrm{H}_{2} \mathrm{O}$ & $\mathrm{CaCl}_{2}$ & -- mg & $\mathrm{Im}^{-3}--$ & -- & $--\mathrm{C}$ & $\mathrm{hol}_{\mathrm{c}} \mathrm{d}$ & $\mathrm{n}^{-3}$ & -- & & \\
\hline Lisím & 5,30 & 4,50 & 4,70 & 77,20 & 1,25 & 0,50 & 0,35 & 4,42 & 6,72 & 29,02 & 28,70 \\
\hline Bordadura & 5,30 & 4,60 & 3,00 & 61,40 & 1,35 & 0,54 & 0,33 & 3,12 & 6,50 & 31,54 & 27,10 \\
\hline
\end{tabular}

Fonte: AGROANÁLISE - Laboratórios Integrados, Cuiabá - MT. (maio/2016). AGROANÁLISE - Laboratórios Integrados, Cuiabá - MT. (May/2016).

A lâmina de água determinada por meio da evapotranspiração contabilizada nos lisímetros, foi aplicada por um sistema de irrigação por aspersão, composto por 6 aspersores (Eco 232 Fabrimar), espaçados em 12 x 12 metros, com Coeficiente de Uniformidade de Christiansen de $86 \%$, sob pressão de 30 m.c.a., proporcionando uma lâmina de água aplicada por hora de $9,76 \mathrm{~mm}$.

Para o cálculo da evapotranspiração de referência - ETo, utilizou-se à metodologia de Penman-Monteith, proposta por Allen et al. (1998), conforme a equação (1):

$$
\mathrm{ETo}=\frac{0,408 \Delta(\mathrm{Rn}-\mathrm{G})+7 \frac{900}{\mathrm{~T}+273} \mathrm{U}_{2}\left(\mathrm{e}_{\mathrm{r}}-\mathrm{e}_{2}\right)}{\Delta+7\left(1+0,3 \mathrm{U}_{2}\right)}
$$

Em que:

ETo - evapotranspiração de referência $\left(\mathrm{mm} \mathrm{dia}^{-1}\right)$;

$\mathrm{Rn}$ - radiação solar líquida sobre a cultura $\left(\mathrm{MJ} \mathrm{m}^{-2} \mathrm{dia}^{-1}\right)$;

$\mathrm{G}$ - densidade do fluxo de calor do solo $\left(\mathrm{MJ} \mathrm{m}^{-2} \mathrm{dia}^{-1}\right)$;

$\mathrm{T}$ - temperatura do ar a dois metros de altura $\left({ }^{\circ} \mathrm{C}\right)$;

$\mathrm{U}_{2}$ - velocidade do vento a dois metros de altura $\left(\mathrm{m} \mathrm{s}^{-1}\right)$;

$\mathrm{e}_{\mathrm{s}}$ - pressão de saturação de vapor $(\mathrm{kPa})$, que é estimada pela média de es (T.máx) e es (T.mín);

$\mathrm{e}_{\mathrm{a}}$ - pressão atual de vapor $(\mathrm{kPa})$;

$\mathrm{e}_{\mathrm{s}}-\mathrm{e}_{\mathrm{a}}$ - déficit de pressão e saturação de vapor $\left(\mathrm{kPa}^{\circ} \mathrm{C}^{-1}\right)$;

$\Delta$ - curva de pressão de vapor $\left(\mathrm{kPa}^{\circ} \mathrm{C}^{-1}\right) \mathrm{e}$;

$\gamma$ - constante psicométrica $\left(\mathrm{kPa}^{\circ} \mathrm{C}^{-1}\right)$.

Utilizou-se de nove microlisímetros de $150 \mathrm{~mm}$ de diâmetro e $300 \mathrm{~mm}$ de altura, alocados ao lado dos lisímetros de pesagem (Figura 1), para determinar a evaporação do solo, de acordo com metodologia de Flumignan, Faria e Lena (2012). A coleta dos dados dos 
microlisímetros foi realizada diariamente e sempre no mesmo horário, as 06:00 e as 18:00 horas, por meio de pesagem manual em balança de precisão, e organizada em planilha para o cálculo diário de variação de massa.

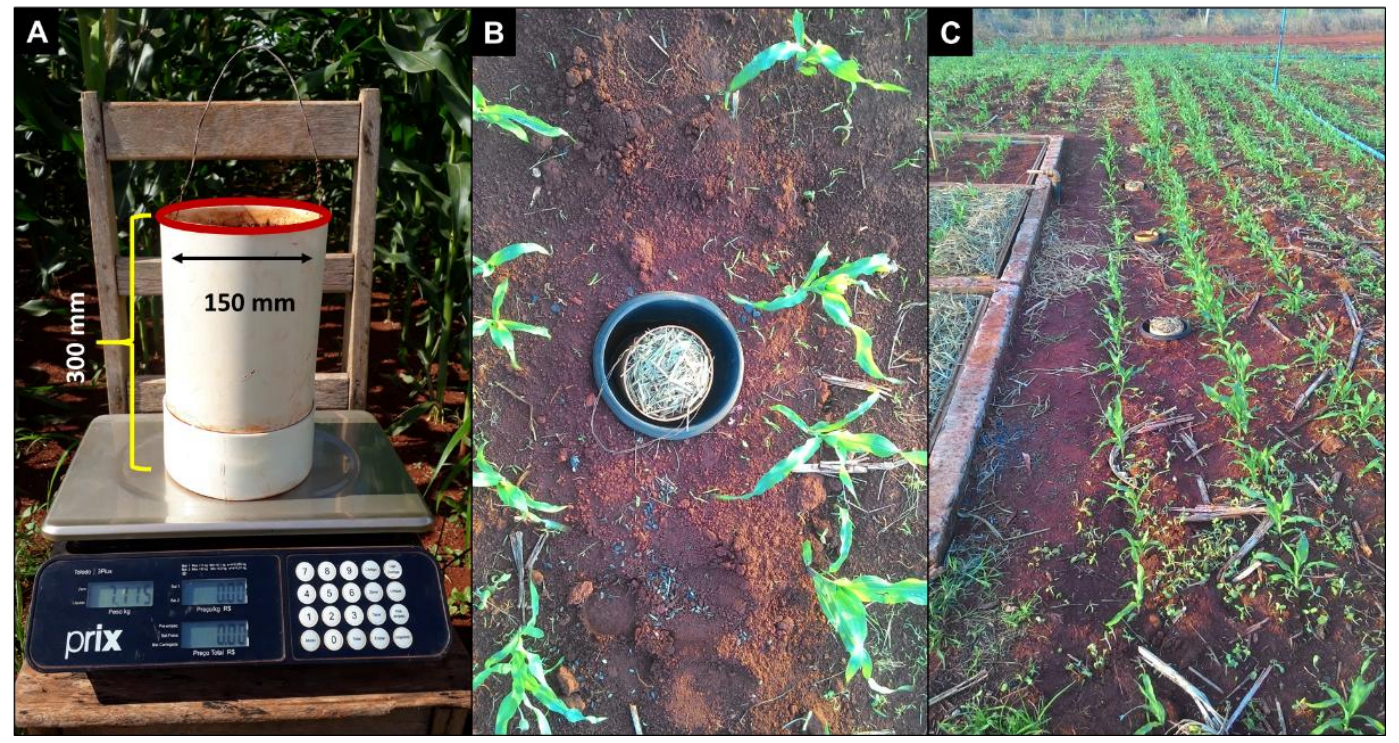

Figura 1. Dimensões dos microlisímetros utilizados no experimento e pesagem dos mesmos no campo (A); microlisímetros instalados nas entrelinhas do milho (B e C). Dimensions of microlysimeters used in the experiment and weighing them in the field (A); microlysimeters installed between the maize lines ( $B$ and $C$ ).

Fonte: Autoria própria. Own authorship.

Para os microlisímetros, realizou-se três repetições para cada tratamento, onde a distribuição dos tratamentos foi realizada por sorteio. A evaporação do solo foi determinada em milímetros ( $\left.\mathrm{E}_{\mathrm{ML}}\right)$, conforme a equação (2):

Em que:

$$
\mathrm{E}_{\mathrm{ML}}=\frac{\Delta \mathrm{N}_{\mathrm{NL}}+\mathrm{P}}{\mathrm{A}_{\mathrm{NL}}}
$$

$\mathrm{E}_{\mathrm{ML}}$ - evaporação do microlisímetro (mm);

$\Delta \mathrm{M}_{\mathrm{ML}}$ - variação de massa dos microlisímetros $(\mathrm{kg})$;

$\mathrm{A}_{\mathrm{ML}}$ - área dos microlisímetros $\left(\mathrm{m}^{2}\right)$;

$\mathrm{P}$ - precipitação ou irrigação $(\mathrm{mm})$.

Os valores da evapotranspiração da cultura (ETc) foram obtidos diariamente através da variação de massa dos lisímetros (Figura 2), no período das 06:00 às 17:00 h, registrados em um Datalogger (CR1000, Campbell Scientific Inc., USA), convertida em mm dia segundo metodologia de Faria, Campeche e Chibana (2006); Mendonça et al. (2007) e Fenner et al. (2019).

As fases fenológicas da cultura foram determinadas de acordo com o boletim FAO - 56 (ALLEN et al., 1998), para a determinação da evapotranspiração da cultura nos diferentes estádios de desenvolvimento, sendo inicial (I), intermediária (II) e final (III). 


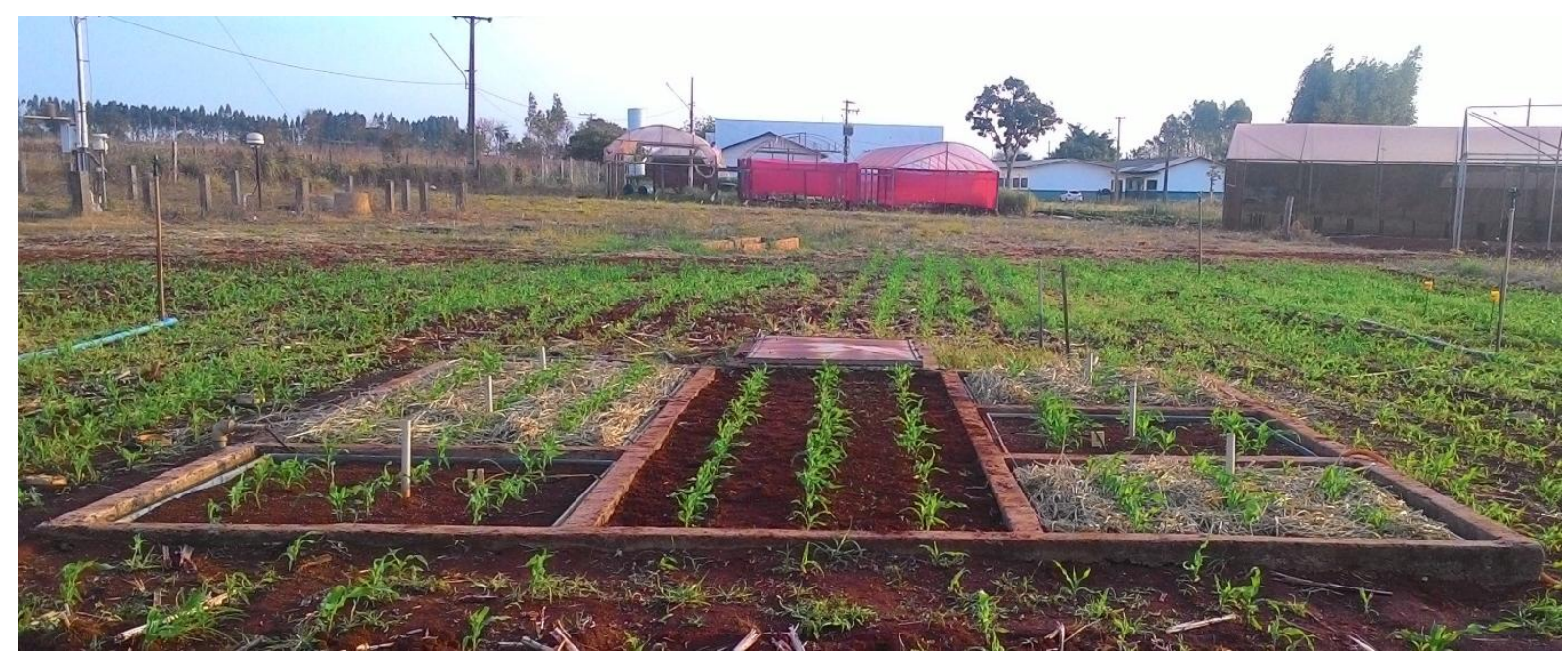

Figura 2. Vista dos seis lisímetros de pesagem de alta precisão, com a disposição dos tratamentos, instalados na área experimental da Universidade do Estado do Mato Grosso, em Tangará da Serra - MT. View of the six high precision lysimeters, with the arrangement of treatments, installed in the experimental area of the State University of Mato Grosso, Tangará da Serra - MT.

Fonte: Autoria própria. Own authorship.

O início da coleta de dados foi aos 15 dias após a emergência da cultura, isso devido a palhada de braquiária ser disposta nos lisímetros no $14^{\circ}$ dia após a emergência do milho, totalizando 97 dias de coleta durante o ciclo da cultura. A variação negativa da massa dos lisímetros em um determinado espaço de tempo corresponde a quantidade de água perdida para a atmosfera, como segue a equação (3), proposta por Campeche (2002):

Em que:

$$
\mathrm{ETc}=\frac{\mathrm{M}_{\mathrm{i}}-\mathrm{M}_{\mathrm{i}-1}+\mathrm{p}}{\mathrm{A} \cdot \Delta \mathrm{T}}
$$

ETc - evapotranspiração da cultura $\left(\mathrm{mm}^{\text {período }}{ }^{-1}\right)$;

$\mathrm{M}_{\mathrm{i}}$ - massa atual do lisímetro;

$\mathrm{M}_{\mathrm{i}-1}$ - massa do lisímetro no tempo anterior;

A - área do lisímetro;

$\Delta \mathrm{T}$ - período de tempo.

P - Precipitação ou irrigação (mm)

Foram coletadas todas as plantas de cada tratamento, onde cada planta corresponde a uma repetição, totalizando 28 repetições. Foram avaliadas as seguintes características: altura de planta (AP); número de fileira por espiga de milho (NFE); número de grãos por fileira (NGF); número de grãos por espiga (NGE); massa seca da parte aérea da planta, coletada no fim do ciclo da cultura (MSP); massa de mil grãos (M1000) e produtividade (PROD).

A colheita foi realizada manualmente, 116 dias após a semeadura. O número de grãos por fileira e o número de fileiras por espiga de milho foi contado manualmente, determinando-se o número de grãos por espiga de milho. Para a massa seca da planta, cada uma com todas as partes do material vegetal, colhidos ao fim do ciclo da cultura, foi acondicionada em estufa de secagem com circulação forçada de ar, com temperatura de aproximadamente $65{ }^{\circ} \mathrm{C}$, durante $72 \mathrm{~h}$, com posterior pesagem do material seco. Para 
determinar a massa de 1000 grãos, estes foram mantidos por $72 \mathrm{~h}$ em estufa de secagem com circulação forçada de ar, com temperatura de $65^{\circ} \mathrm{C}$, posteriormente, realizou-se a pesagem com uso de balança eletrônica de precisão, a umidade dos grãos foi corrigida a 13\%. A produtividade de grãos foi determinada pela colheita das plantas de cada tratamento (28 plantas), convertendo para $\mathrm{kg} \mathrm{ha}^{-1}$, com umidade dos grãos corrigida a $13 \%$.

Os dados obtidos foram testados quanto a sua normalidade, e submetidos à análise de variância pelo teste $\mathrm{F}$, sendo as médias comparadas pelo teste de Tukey a 5\% de probabilidade, utilizando-se o software Sisvar versão 5.6 (FERREIRA, 2011).

\section{RESULTADOS E DISCUSSÃO}

Na figura 3 apresentam-se os valores médios climáticos obtidos durante os meses de condução do experimento, foi aplicado $595,5 \mathrm{~mm}$ de água via irrigação e $262,1 \mathrm{~mm}$ proveniente das chuvas, condições esperadas para a região em estudo.

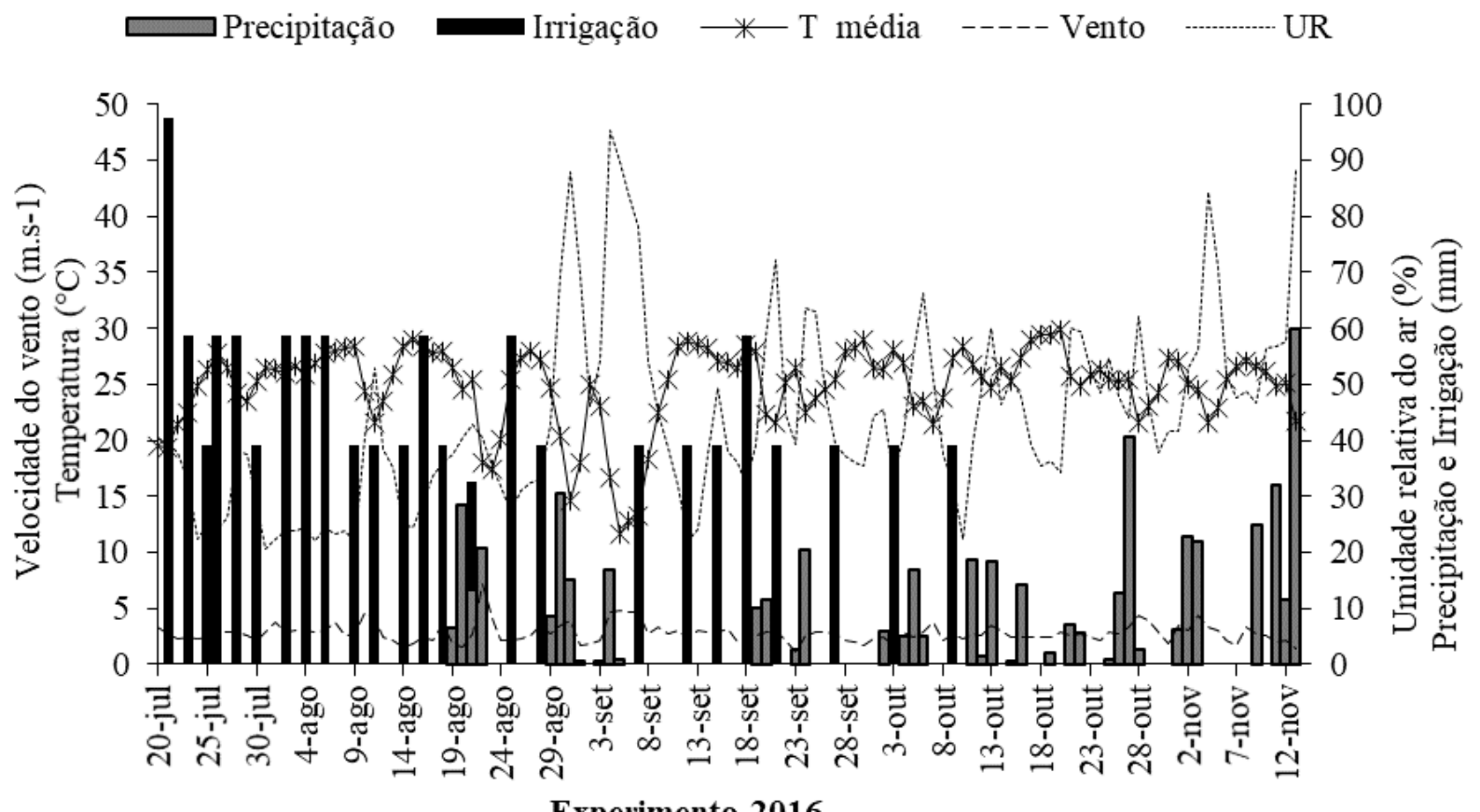

Experimento 2016

Figura 3. Dados climáticos desde a semeadura até a colheita do milho. Tangará da Serra, MT, 2016. Climatic data from sowing to harvest maize. Tangará da Serra, MT, 2016.

Fonte: Estação meteorológica automática instalada no campo experimental da Universidade do Estado de Mato Grosso, em Tangará da Serra - MT. Research data. Automatic meteorological station installed in the experimental field of the State University of Mato Grosso, in Tangará da Serra - MT.

$\mathrm{Na}$ fase de germinação e crescimento inicial da cultura a irrigação foi essencial para o bom desenvolvimento, temperaturas elevadas e baixa umidade relativa do ar favorecem o desenvolvimento da cultura desde que não ocorra déficit hídrico, isso pode ser notado pelo número de irrigações realizadas na fase inicial da cultura.

A dinâmica entre os valores da evapotranspiração de referência ao longo do desenvolvimento do milho variou entre 0,60 e 5,69 $\mathrm{mm} \mathrm{dia}^{-1}$. Os valores acumulados da ETo por estádio de desenvolvimento do milho foram de 121,$65 ; 138,84$ e $65,05 \mathrm{~mm}$, para a fase 
inicial (I), intermediária (II) e final (III), respectivamente, totalizando 325,54 $\mathrm{mm}$ para todo o ciclo da cultura (Tabela 2). A média geral da ETo foi 3,35 $\mathrm{mm} \mathrm{dia}^{-1}$.

Tabela 2. Valores médios da evapotranspiração de referência (ETo) ao longo dos dias após a emergência do milho, de acordo com o estádio fenológico. Tangará da Serra - MT, 2016. Mean values of reference evapotranspiration (ETo) along the days after emergence of maize, according to the phenological stage. Tangará da Serra - MT, 2016.

\begin{tabular}{lcccc}
\hline \multirow{2}{*}{ Parâmetros } & \multicolumn{5}{c}{ Estádios fenológicos } \\
\cline { 2 - 5 } & I & II & III & Total/Média \\
\hline Duração (dias) & 35 & 40 & 21 & 96 \\
ETo $\left(\mathrm{mm} \mathrm{dia}^{-1}\right)$ & 3,48 & 3,47 & 3,10 & 3,35 \\
ETo $(\mathrm{mm})$ & 121,65 & 138,84 & 65,05 & 325,54 \\
\hline
\end{tabular}

Fonte: Autoria própria. Own authorship.

A ETc do milho obtida em condições de solo sem cobertura e em solo com cobertura morta, com 4 e $8 \mathrm{t} \mathrm{ha}^{-1}$ apresentam mesma tendência (Tabela 3), indicando que a quantidade de cobertura vegetal sobre o solo não proporcionou diferenças nos valores da ETc. Porém, os valores de ETc nos tratamentos com cobertura de solo mostraram-se inferiores aos valores do solo sem cobertura.

Tabela 3. Valores médios da evapotranspiração da cultura (ETc) para o tratamento sem cobertura de solo, com $4 \mathrm{t} \mathrm{ha}^{-1}$ e $8 \mathrm{t} \mathrm{ha}^{-1}$ de cobertura de solo, de acordo com o estádio fenológico do milho. Tangará da Serra - MT, 2016. Average crop evapotranspiration (ETc) values for the treatment without soil cover, with $4 \mathrm{th} \mathrm{h}^{-1}$ and $8 \mathrm{th} \mathrm{h}^{-1}$ of soil cover, according to the maize phenological stage. Tangará da Serra - MT, 2016.

\begin{tabular}{lcccc}
\hline \multirow{2}{*}{ Parâmetros } & \multicolumn{4}{c}{ Estádios fenológicos } \\
\cline { 2 - 5 } & I & II & III & Total/Média \\
\hline Duração (dias) & 35 & 40 & 21 & 96 \\
\hline ETc - Sem cobertura (mm) & 115,96 & 159,05 & 60,93 & 335,94 \\
ETc - Sem cobertura $\left(\mathrm{mm} \mathrm{dia}{ }^{-1}\right)$ & 3,31 & 3,98 & 2,90 & 3,40 \\
ETc - Cobertura 4 t (mm) & 106,69 & 152,05 & 45,86 & 304,60 \\
ETc - Cobertura 4 t (mm dia & 3,05 & 3,80 & 2,18 & 3,01 \\
ETc - Cobertura 8 t $(\mathrm{mm})$ & 110,77 & 157,94 & 63,34 & 332,05 \\
ETc - Cobertura 8 t $\left(\mathrm{mm} \mathrm{dia}^{-1}\right)$ & 3,16 & 3,95 & 3,02 & 3,38 \\
\hline
\end{tabular}

Fonte: Autoria própria. Own authorship.

Resultados semelhantes foram encontrados por Murga-Orrillo et al. (2016), que estudando a evapotranspiração da cultura do milho da cultivar BRS 1010 em Boa Vista, RR, observaram que a evapotranspiração da cultura com e sem cobertura de solo foram semelhantes, entretanto, os valores de ETc com cobertura foram menores que os valores do solo descoberto.

No solo sem cobertura, a ETc acumulada foi 335,94 mm, com mínima de 0,69 $\mathrm{mm} \mathrm{dia}^{-}$ ${ }^{1}$, máxima de $6,58 \mathrm{~mm} \mathrm{dia}^{-1}$ e média de $3,40 \mathrm{~mm} \mathrm{dia}^{-1}$. Com cobertura de $4 \mathrm{t} \mathrm{ha}^{-1}$, a ETc total foi $304,60 \mathrm{~mm}$, com variações entre 0,20 e $6,56 \mathrm{~mm} \mathrm{dia}^{-1}$ e média de $3,01 \mathrm{~mm} \mathrm{dia}{ }^{-1}$. Com cobertura de $8 \mathrm{t} \mathrm{ha}^{-1}$ no solo, o acumulado foi $332,05 \mathrm{~mm}$, com mínima de $0,34 \mathrm{~mm} \mathrm{dia}{ }^{-1}$, máxima de 7,27 $\mathrm{mm} \mathrm{dia}^{-1}$ e, média de $3,38 \mathrm{~mm} \mathrm{dia}^{-1}$. Estes resultados mostram que a 
cobertura morta do solo influenciou no consumo hídrico da cultura de milho durante todo seu ciclo. A palhada promove uma barreira mecânica e térmica ao solo, propiciando uma melhor conservação da água e reduzindo as perdas por evapotranspiração (GAVA et al., 2013).

A ETc acumulada foi reduzida em 9,32 e 1,16\% nos tratamentos com cobertura de 4 e $8 \mathrm{t} \mathrm{ha}^{-1} \mathrm{e}$, em questão de milímetros, a redução foi de $31,34 \mathrm{~mm}$ e 3,9 mm, comprando-se com o tratamento sem cobertura do solo. Essa mesma tendência foi observada por Murga-Orrillo et al. (2016), que avaliaram a influência da cobertura morta na evapotranspiração do milho, no município de Boa Vista, com ciclo de 104 dias, e verificaram que os valores de ETc no cultivo de milho com cobertura mostraram-se inferiores aos valores do solo descoberto, com $16,7 \%$ a menos de consumo de água no cultivo com cobertura, com valores de ETc durante o ciclo da cultura, em solo sem e com cobertura foram de 421,5 e $351,0 \mathrm{~mm}$, respectivamente, com médias diárias de 4,1 $\mathrm{mm} \mathrm{dia}^{-1}$ para solo sem cobertura e $3,4 \mathrm{~mm} \mathrm{dia}^{-1}$ para solo com cobertura.

Silva et al. (2015a), determinando a evapotranspiração e os coeficientes de cultura para a melancia irrigada por gotejamento, cultivada sob palhada de milheto e preparo convencional, em Teresina - PI, verificaram redução de 7,5\% na ETc da cultura em cultivo sobre cobertura de solo em comparação ao preparo convencional, com ETc acumulada aos 64 dias após transplantio da cultura de 206,68 mm (solo coberto) e 222,26 mm (cultivo convencional).

Trabalhos que determinam o consumo de água do milho em cultivos convencionais são mais comuns. Santos et al. (2014), trabalhando com cultivo convencional de milho verde em Mossoró - RN, determinaram a evapotranspiração de 300,5 mm para um ciclo 77 dias. Souza et al. (2015), avaliando milho da cultivar Caatingueiro, de forma convencional, na Embrapa Semiárido, em Petrolina - PE, determinou a evapotranspiração de 387,1 mm, para um ciclo da cultura de 109 dias.

Os valores de evapotranspiração e a capacidade de reter maior umidade podem variar de acordo com a utilização ou não de cobertura do solo, bem como, com o tipo e a quantidade de material utilizado, o que pode influenciar também na dinâmica de uso de água pela planta (KLEIN; KLEIN, 2015).

No tratamento sem cobertura de solo, houve maior perda de água do solo por evaporação e, menor transpiração da planta. Nos tratamentos com cobertura de solo com 4 e 8 $\mathrm{t} \mathrm{ha}^{-1}$, a tendência foi o oposto (Figura 4).

Os maiores valores de evaporação do solo foram observados com cultivo de milho sem cobertura de solo, com evaporação total de $133,78 \mathrm{~mm}$ e, média diária de 1,39 $\mathrm{mm} \mathrm{dia}^{-1}$.

Nos tratamentos com 4 e $8 \mathrm{t} \mathrm{ha}^{-1}$ de cobertura de braquiária, houve menor perda de água do solo, com total acumulado de 64,14 e 59,04 mm, e médias diárias de evaporação do solo de 0,67 e $0,62 \mathrm{~mm} \mathrm{dia}^{-1}$, respectivamente. O T3, solo com cobertura de $8 \mathrm{t} \mathrm{ha}^{-1}$, proporcionou maior redução da evaporação (Figura 4A). 


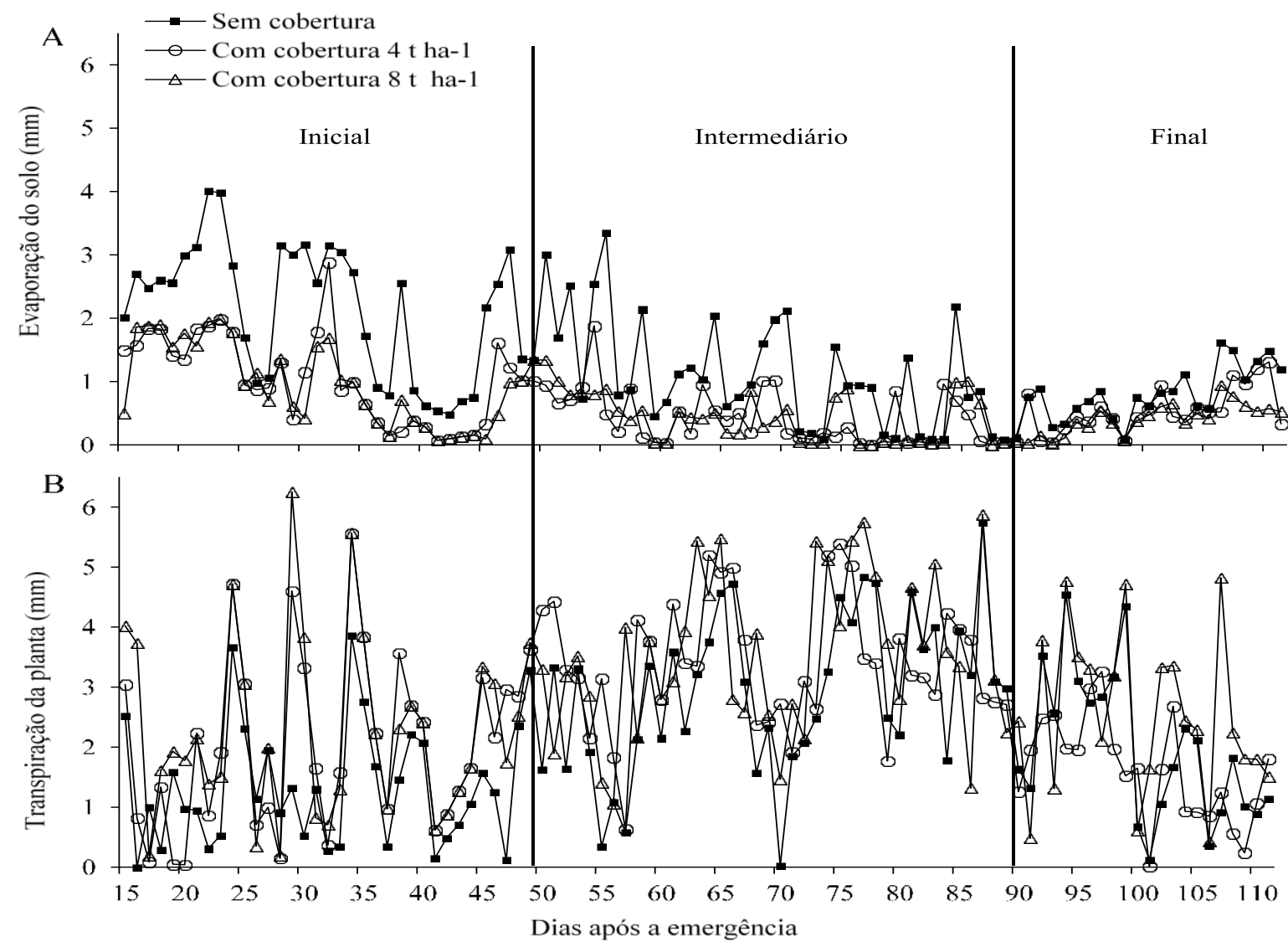

Figura 4. Valores diários de evaporação do solo (A), transpiração da planta (B), para os tratamentos sem cobertura do solo, $4 \mathrm{t} \mathrm{ha}^{-1} \mathrm{e} 8 \mathrm{t} \mathrm{ha}^{-1}$ de cobertura do solo. Daily values of soil evaporation (A), plant transpiration (B), for treatments without soil cover, 4 tha $a^{-1}$ and 8 t ha $a^{-1}$ of soil cover.

Fonte: Autoria própria. Own authorship.

A utilização de palhada sobre o solo altera a relação solo-água, uma vez que o processo de evaporação do solo é reduzido, e consequentemente haverá mudanças na evapotranspiração da cultura, tal fato, pode reduzir a frequência de irrigação, resultando em economia nos custos de operação do sistema de irrigação (MORAES et al., 2016).

Houve redução de perda de água do solo por evaporação de 69,64 mm, quando utilizado cobertura de $4 \mathrm{t} \mathrm{ha}^{-1} \mathrm{e}$, com o $8 \mathrm{t} \mathrm{ha}^{-1}$ a redução foi de 74,74 mm, o que representa redução de 52,02 e 56,00\% da evaporação do solo, respectivamente. Allen et al. (1998) afirmaram que o uso de coberturas mortas na superfície do solo, especialmente quando a cultura é pequena, é uma forma de manejo que reduz a evaporação do solo substancialmente.

Para a transpiração da planta, foi o inverso da evaporação do solo, em que os tratamentos com cobertura, proporcionaram os maiores valores de transpiração da planta. A transpiração total foi de 201,81; 240,60 e 272,96 mm, com médias diárias de 2,10; 2,50 e 2,84 $\mathrm{mm}$ para os tratamentos sem cobertura de solo, com $4 \mathrm{t} \mathrm{ha}^{-1}$ de cobertura de solo e $8 \mathrm{t} \mathrm{ha}^{-1}$ de cobertura de solo, respectivamente em relação ao tratamento sem cobertura (Figura 4B).

A distribuição dos valores diários de evaporação, transpiração e a evapotranspiração da cultura podem ser observados na Figura 5, onde nota-se que os valores de evaporação para solo sem cobertura são maiores que em solos com cobertura, para a transpiração observamos 
o contrário, sendo que em solos sem cobertura a transpiração da planta é reduzida.

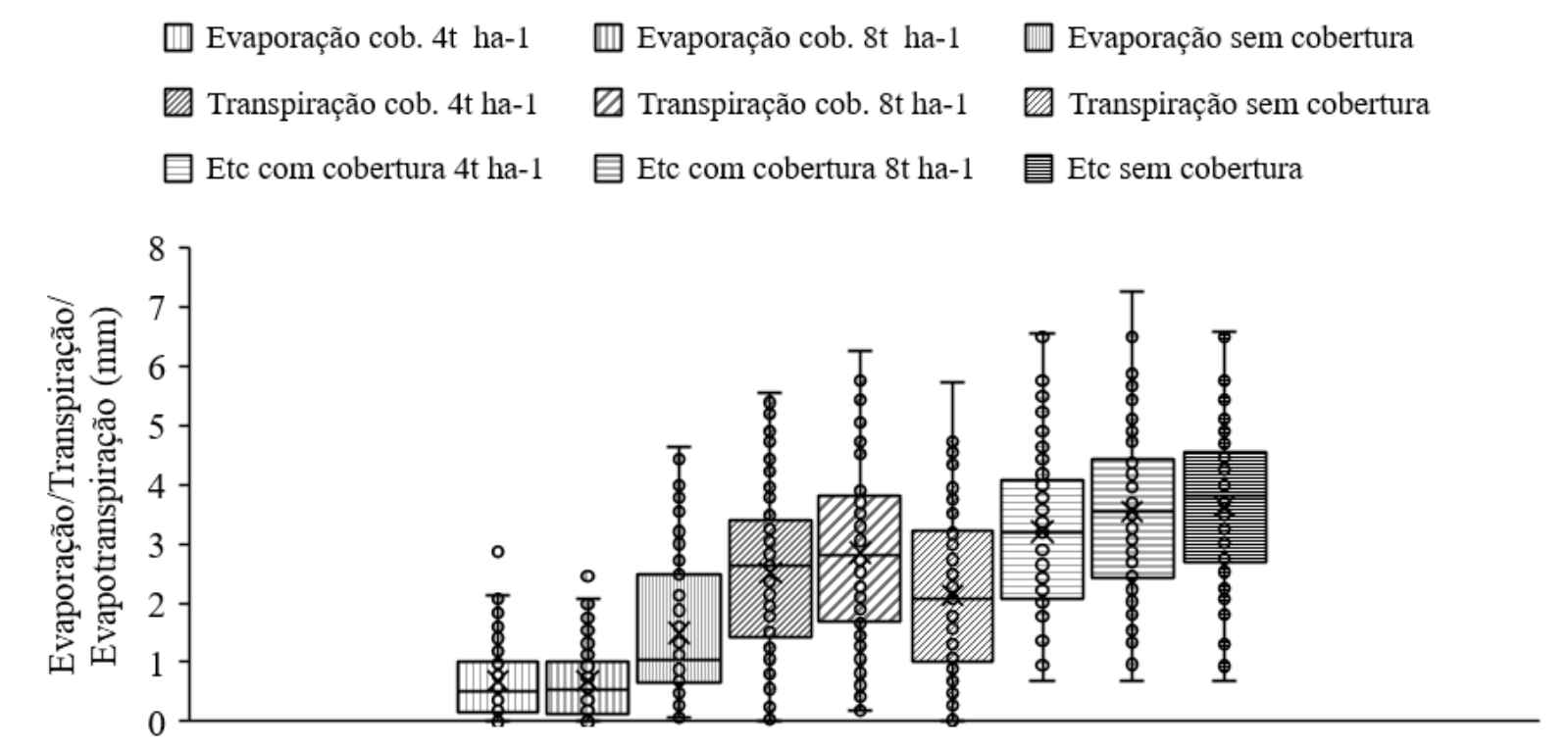

Figura 5. Distribuição dos valores de evaporação e transpiração, para os tratamentos sem cobertura do solo, $4 \mathrm{t} \mathrm{ha} \mathrm{a}^{-1}$ e $8 \mathrm{t} \mathrm{ha}^{-1}$ de cobertura do solo. Tangará da Serra - MT. Distribution of evaporation and transpiration values, for treatments without soil cover, 4 t ha $a^{-1}$ and 8 t ha $a^{-1}$ soil cover. Tangará da Serra - MT.

Fonte: Autoria própria. Own authorship.

O milho cultivado com cobertura proporcionou alterações na evapotranspiração da cultura, positivamente, já que de acordo com Barros e Calado (2014), a transpiração depende do suprimento de água do solo, logo, a cobertura reduziu a perda de água do solo, mantendo-o com maior umidade, com isso, a transpiração foi aumentada.

Ainda, Barros e Calado (2014), afirmaram que a transpiração proporciona efeitos benéficos à planta, bem como o resfriamento da folha, no processo fotossintético, em que o $\mathrm{CO}_{2}$ é absorvido e a aceleração da ascensão da seiva do xilema, contribuindo para o aumento na absorção de nutrientes do solo, que consequentemente acarretará em incrementos da produtividade da planta cultivada.

Comparando a transpiração nos tratamentos sem cobertura de solo e com cobertura, observou-se aumento de 38,79 mm com a utilização da cobertura de $4 \mathrm{t} \mathrm{ha}^{-1}$ e $71,15 \mathrm{~mm}$ com cobertura de $8 \mathrm{t} \mathrm{ha}^{-1}$.

Para o valor médio de evapotranspiração da cultura do milho sem cobertura de solo, a evaporação do solo corresponde a 39,93\% e a transpiração 60,08\%. No cultivo com cobertura de $4 \mathrm{t} \mathrm{ha}^{-1}$, a evaporação representa $21,01 \%$ e a transpiração $78,98 \%$ e com 8 t ha ${ }^{-1}$ a evaporação do solo corresponde a 17,79\% e a transpiração $82,20 \%$.

Mediante estes resultados, verificou-se que, além das modificações observadas na evapotranspiração, a palhada também altera a forma na qual a água é utilizada pela planta, em que os tratamentos com cobertura de solo proporcionaram redução da evaporação e consequente aumento da transpiração.

$\mathrm{Na}$ Tabela 4 encontra-se o resumo da análise de variância das características 
agronômicas avaliadas, em que todas as variáveis analisadas apresentaram diferenças significativas entre os tratamentos. $\mathrm{O}$ tratamento sem cobertura do solo proporcionou as menores médias para todas as variáveis e entre o tratamento com 4 e $8 \mathrm{t} \mathrm{ha}^{-1}$ não houve diferenças estatísticas. A cobertura do solo influenciou positivamente nas características produtivas da planta de milho.

Tabela 4. Resumo da análise de variância (teste F), para a altura de planta (AP), número de grãos por fileira (NGF), número de grãos por espiga de milho (NGE), massa seca da planta (MSP), massa de mil grãos (M1000), produtividade (PROD), em Tangará da Serra - MT. Summary of analysis of variance ( $F$ test) for plant height (AP), number of grains per row $(N G F)$, number of grains per spike of corn (NGE), plant dry mass (DM), mass of a thousand grains (M1000), productivity (PROD), in Tangará da Serra - MT.

\begin{tabular}{ccccccc}
\hline Variáveis & GL & SQ & QM & F & DMS & CV $(\%)$ \\
\hline AP & 2 & 0,15 & 0,07 & $6,86^{* *}$ & 0,066 & 4,81 \\
NGF & 2 & 339,50 & 169,75 & $29,52^{* *}$ & 1,544 & 7,01 \\
NGE & 2 & 120958,38 & 60479,19 & $17,05^{* *}$ & 38,371 & 9,56 \\
MSP & 2 & 37149,08 & 18574,54 & $11,65^{* *}$ & 25,730 & 20,71 \\
M1000 & 2 & 0,002 & 0,001 & $2,70^{\text {ns }}$ & 0,014 & 9,11 \\
PROD & 2 & 52041284,09 & 26020642,05 & $22,73^{* *}$ & 689,32 & 11,41 \\
\hline
\end{tabular}

${ }^{\bar{*} *}$ significativo $(\mathrm{p} \leq 0,01)$ e ${ }^{*}$ significativo $(\mathrm{p} \leq 0,05)$, e ${ }^{\mathrm{ns}}$ não significativo pelo teste $\mathrm{F}$. Extraído da análise de variância. ${ }^{* *}$ significant $(p \leq 0.01)$ and ${ }^{*}$ significant $(p \leq 0.05)$, and ${ }^{n s}$ not significant by the $F$ test. Extracted from the variance analysis.

Fonte: Autoria própria. Own authorship.

$\mathrm{O} \mathrm{T} 1$, solo sem cobertura, proporcionou os menores valores de número de grãos por fileira, número de grãos por espiga de milho, massa seca, peso de 1000 grãos e produtividade, com diferenças estatísticas dos tratamentos com cobertura de 4 t ha-1 e 8 t ha-1, porém, entre estes, não ocorreram diferenças significativas (Tabela 5).

Tabela 5. Altura de planta (AP), número de grãos por fileira de milho (NGF), número de grãos por espiga de milho (NGE), massa seca de planta (MSP), massa de mil grãos (M1000) e produtividade (PROD), para os três tratamentos. Plant height (AP), number of grains per row of maize (NGF), number of grains per spike of corn (NGE), plant dry mass (MSP), mass of thousand grains (M1000) and productivity (PROD), for the three treatments.

\begin{tabular}{lcccccc}
\hline TRATAMENTO & AP $(\mathrm{m})$ & NGF & NGE & $\begin{array}{c}\text { MSP } \\
(\mathrm{g})\end{array}$ & M1000 (Kg) & $\begin{array}{c}\text { PROD } \\
\left(\mathrm{Kg} \mathrm{ha}^{-1}\right)\end{array}$ \\
\hline Sem cobertura & $2,08 \mathrm{~b}$ & $31,39 \mathrm{~b}$ & $569,28 \mathrm{~b}$ & $164,01 \mathrm{~b}$ & $0,243 \mathrm{a}$ & $8264,67 \mathrm{~b}$ \\
$4 \mathrm{t} \mathrm{ha}^{-1}$ & $2,17 \mathrm{a}$ & $35,32 \mathrm{a}$ & $647,78 \mathrm{a}$ & $200,87 \mathrm{a}$ & $0,253 \mathrm{a}$ & $9929,18 \mathrm{a}$ \\
$8 \mathrm{t} \mathrm{ha}^{-1}$ & $2,18 \mathrm{a}$ & $35,92 \mathrm{a}$ & $651,64 \mathrm{a}$ & $213,60 \mathrm{a}$ & $0,256 \mathrm{a}$ & $9939,52 \mathrm{a}$ \\
\hline
\end{tabular}

Nota: Médias seguidas pela mesma letra, na coluna, indicam ausência de diferenças significativas $(\mathrm{p} \leq 0,01)$, pelo teste Tukey. Note: Means followed by the same letter in the column indicate absence of significant differences $(p \leq 0.01)$, by the Tukey test.

Fonte: Autoria própria. Own authorship.

Os tratamentos com cobertura de solo apresentaram as maiores médias para todas as variáveis avaliadas, com exceção da massa de 1000 grãos.

O cultivo de milho com cobertura manteve o solo com maior umidade, fato que 
proporcionou melhores condições para o desenvolvimento da planta, contribuindo para aumentar os valores das variáveis produtivas avaliadas. O número de grãos por fileira é determinado no estádio V14, onde são formados os óvulos potenciais e fecundados em R1. Dessa forma, para que todos os óvulos potenciais sejam fecundados, são necessárias condições de umidade do solo favorável à cultura, porém nessa fase o déficit hídrico pode causar grandes reduções em número de grãos por fileira e, consequentemente, grãos por espiga (RITCHIE; HANWAY; BENSON, 2003).

Maldaner et al. (2014), descrevem que a disponibilidade hídrica na fase de fecundação e enchimento de grãos é essencial ao bom desenvolvimento dos grãos e aumento na produtividade. Neste trabalho, nos tratamentos com cobertura de solo, houve maior quantidade de água disponível para a planta, favorecendo a fecundação e o enchimento dos grãos.

A massa seca de cada planta de milho apresentou valores de 164,01; 200,87 e 213,60 g para os tratamentos sem cobertura, com cobertura de 4 e $8 \mathrm{t} \mathrm{ha}^{-1}$, respectivamente. Para a variável massa de 1000 grãos, não houve diferenças estatísticas entre os três tratamentos avaliados.

A produtividade do milho foi de 8264,$67 ; 9929,18$ e $9939,52 \mathrm{~kg} \mathrm{ha}^{-1}$, para os tratamentos sem cobertura, com cobertura de 4 e $8 \mathrm{t} \mathrm{ha}^{-1}$, respectivamente. A produtividade obtida neste experimento foi maior que a média estimada para a segunda safra de 2018/2019, que segundo a Conab (2019) deve atingir $6150,0 \mathrm{~kg} \mathrm{ha}^{-1}$. Isso porque, a cultura foi conduzida em condições ideais de cultivo, e sem restrição hídrica.

Essas diferenças entre os tratamentos sem e com cobertura de solo podem ser atribuídas aos efeitos da palhada, que proporcionaram alterações na dinâmica de uso da água pela planta de milho, uma vez que a evaporação do solo foi reduzida, enquanto que a transpiração da planta foi aumentada, promovendo incremento na produtividade (ALBUQUERQUE et al., 2013).

Para o cultivo de milho safrinha na região Noroeste do Estado de São Paulo, Silva et al. (2012) recomendaram, para a obtenção da maior produtividade de matéria seca de forragem com grãos $\left(23,6 \mathrm{t} \mathrm{ha}^{-1}\right)$, irrigação com reposição de $100 \%$ da evapotranspiração da cultura em sistema de plantio direto com uma quantidade inicial de palhada de $7,7 \mathrm{tha}^{-1}$.

\section{CONCLUSÃO}

A evaporação do solo foi reduzida em 69,64 mm (52,02\%) com cobertura de $4 \mathrm{t} \mathrm{ha}^{-1} \mathrm{e}$ em 74,74 mm (56,00\%) com $8 \mathrm{t} \mathrm{ha}^{-1}$ de palhada, em relação ao solo sem cobertura.

Para a transpiração da planta, houve aumento de 38,79 (16,12\%) e 71,15 mm (26,06\%) quando utilizado cobertura de solo de 4 e $8 \mathrm{t} \mathrm{ha}^{-1}$ de palhada de braquiária, respectivamente, em relação ao solo sem cobertura.

A evapotranspiração acumulada foi de 335,94; 304,60 e 332,05 mm e médias diárias de 3,$40 ; 3,01$ e $3,38 \mathrm{~mm} \mathrm{dia}^{-1}$, respectivamente, para o tratamento sem cobertura de solo, com $4 \mathrm{e}$ $8 \mathrm{t} \mathrm{ha}^{-1}$ de cobertura. 
Houve incremento na produtividade do milho cultivado com cobertura do solo em relação ao sem cobertura, com médias de 8264,67; 9929,18 e 9939,52 kg ha-1 , para os tratamentos sem cobertura, com cobertura de 4 e $8 \mathrm{t} \mathrm{ha}^{-1}$ de palhada de braquiária.

\section{REFERÊNCIAS BIBLIOGRÁFICAS}

ALBUQUERQUE, A. W.; SANTOS, J. R.; FILHO, G. M.; REIS, L. S. Plantas de cobertura e adubação nitrogenada na produção de milho em sistema de plantio direto. Revista Brasileira de Engenharia Agrícola e Ambiental, Campina Grande, v. 17, n. 7, p.721-726, 2013. Disponível em: http://dx.doi.org/10.1590/S1415-43662013000700005. Acesso em: 02 dez. 2017.

ALLEN, R. G.; PEREIRA, L. S.; RAES, D.; SMITH, M. Crop evapotranspiration: guidelines for computing crop requirements. Roma: FAO Irrigation and Drainage Paper 56, 1998. 300 p. Disponível em: http://www.fao.org/3/X0490E/X0490E00.htm. Acesso em: 29 out. 2017.

BARBIERI, J. D.; DALlACORT, R.; SANTI, A.; ROCHA, R. P.; CARVALHO, M. A. C. Zoneamento agroclimático de amendoinzeiro para a Bacia do Alto Paraguai (MT). Pesquisa Agropecuária Tropical, Goiânia, v. 45, n. 2, p.231-240, 2015. Disponível em: http://dx.doi.org/10.1590/1983-40632015v4532985. Acesso em: 25 out. 2019.

BARros, J. F. C.; CALADO, J. G. A cultura do milho. Évora: Universidade de Évora, 2014. $52 \mathrm{p}$.

CAMPECHE, L. F. S. M. Construção, calibração e análise de funcionamento de lisímetros de pesagem para determinação da evapotranspiração da cultura da lima ácida 'Tahiti' (Citrus latifolia Tan.). 2002. 67 f. Tese (Doutorado em Irrigação e Drenagem) - Escola Superior de Agricultura "Luiz de Queiroz", Universidade de São Paulo, Piracicaba, 2002. Disponível em: http://www.teses.usp.br/teses/disponiveis/11/11143/tde-05082002160324/publico/luis.pdf. Acesso em: 07 nov. 2017.

COMPANHIA NACIONAL DE ABASTECIMENTO - CONAB. Acompanhamento de safra brasileira: grãos, - safra 2018/2019, sexto levantamento, v. 6, n. 6. Brasília: CONAB, 2019. Disponível em: https://www.conab.gov.br/info-agro/safras/graos. Acesso em: 10 abr. 2019.

DALlACORT, R.; MARTINS, J. A.; INOUE, M. H.; FREITAS, P. S. L.; COLETTI, A. J. Distribuição das chuvas no município de Tangará da Serra, médio norte do Estado de Mato Grosso, Brasil. Acta Scientiarum. Agronomy, Maringá, v. 33, n. 2, p.193-200, 2011. Disponível em: http://dx.doi.org/10.4025/actasciagron.v33i2.5838. Acesso em: 10 out. 2019.

EMPRESA BRASILEIRA DE PESQUISA AGROPECUÁRIA - EMBRAPA. Sistema brasileiro de classificação de solos. 3. ed. Brasília: Embrapa Informação Tecnológica, 2013. $353 \mathrm{p}$.

FARIA, R. T.; CAMPECHE, L. F. S. M.; CHIBANA, E. Y. Construção e calibração de lisímetros de alta precisão. Revista Brasileira de Engenharia Agrícola e Ambiental, 
Campina Grande, v. 10, n. 1, p.237-242, 2006. Disponível em: http://dx.doi.org/10.1590/S1415-43662006000100035. Acesso em: 10 dez. 2017.

FENNER, W.; DALLACORT, R.; FARIA JUNIOR, C. A.; FREITAS, P. S. L.; QUEIROZ, T. M.; SANTI, A. Development, calibration and validation of weighing lysimeters for measurement of evapotranspiration of crops. Revista Brasileira de Engenharia Agrícola e Ambiental, Campina Grande, v. 23, n. 4, p.297-302, 2019. Disponível em: http://dx.doi.org/10.1590/1807-1929/agriambi.v23n4p297-302. Acesso em: 25 mar. 2019.

FERREIRA, D. F. Sisvar: um sistema computacional de análise estatística. Ciência e Agrotecnologia, Lavras, v. 35, n. 6, p.1039-1042, 2011. Disponível em: http://dx.doi.org/10.1590/S1413-70542011000600001. Acesso em: 01 nov. 2017.

FLUMIGNAN, D. L.; FARIA, R. T.; LENA, B. P. Test of a microlysimeter for measurement of soil evaporation. Engenharia Agrícola, Jaboticabal, v. 32, n. 1, p.80-90, 2012. Disponível em: http://dx.doi.org/10.1590/S0100-69162012000100009. Acesso em: 25 out. 2017.

GAVA, R.; FREITAS, P. S. L.; FARIA, R. T.; REZENDE, R.; FRIZZONE, J. A. Soil water evaporation under densities of coverage with vegetable residue. Engenharia Agrícola, Jaboticabal, v. 33, n. 1, p.89-98, 2013. Disponível em: http://dx.doi.org/10.1590/S010069162013000100010. Acesso em: 10 dez. 2017.

KLEIN, C.; KLEIN, V. A. Strategies to improve the retention and availability of soil water. Electronic Journal of Management, Education and Environmental Technology, Santa Maria, v. 19, n. 1, p.21-29, 2015. Disponível em: http://dx.doi.org/10.5902/2236117014990. Acesso em: 12 fev. 2019.

MALDANER, L. J.; HORING, K.; SCHNEIDER, J. F.; FRIGO, J. P.; AZEVEDO, K. D.; GRZESIUCK, A. E. Exigências agroclimáticas da cultura do milho (Zea mays). Revista Brasileira de Energia Renováveis, Curitiba, v. 3, n. 1, p.13-23, 2014. Disponível em: https://revistas.ufpr.br/rber/article/view/36915/pdf_11. Acesso em: 05 abr. 2019.

MENDONÇA, J. C.; SOUSA, E. F.; BERNARDO, S.; SUGAWARA, M. T.; PEÇANHA, A. L.; GOTTARDO, R. D. Determinação do coeficiente cultural (Kc) do feijoeiro (Phaseolus vulgaris L.), em Campos dos Goytacazes, RJ. Revista Brasileira de Engenharia Agrícola e Ambiental, Campina Grande, v. 11, n. 5, p.471-475, 2007. Disponível em: http://dx.doi.org/10.1590/S1415-43662007000500004. Acesso em: 03 nov. 2017.

MORAES, M. T.; DEBIASI, H.; FRANCHINI, J. C.; SILVA, V. R. Benefícios das plantas de cobertura sobre as propriedades físicas do solo. 2016. In: TIECHER, T. (org.). Manejo e conservação do solo e da água em pequenas propriedades rurais no sul do Brasil: Práticas alternativas de manejo visando a conservação do solo e da água. Porto Alegre: UFRGS, 2016. cap. 03, p. 34-48.

MURGA-ORRILLO, H.; ARAÚJO, W. F.; ABANTO-RODRIGUEZ, C.; SAKAZAKI, R. T.; BARDALES-LOZANO, R. M.; POLO-VARGAS, A. R. Influência da cobertura morta na evapotranspiração, coeficiente de cultivo e eficiência de uso de água do milho cultivado em cerrado. Irriga, Botucatu, v. 21, n. 2, p.352-364, 2016. Disponível em: https://doi.org/10.15809/irriga.2016v21n2p352-364. Acesso em: 10 nov. 2017. 
RHODEN, A. C.; FELDMANN, N. A.; MUHL, F. R.; RITTER, A. F. S.; MOREIRA, A. A importância da água e da gestão dos recursos hídricos. Revista de Ciências Agroveterinárias e Alimentos, Itapiranga, v. 1, n. 1, p.91-108, 2016. Disponível em: http://revista.faifaculdades.edu.br/index.php/cava/article/view/196/91. Acesso em: 18 fev. 2019.

RITCHIE, S. W.; HANWAY, J. J.; BENSON, G. O. Como a planta de milho se desenvolve. Piracicaba: Potafos, 2003. 20 p. (Informações Agronômicas, 103). Disponível em: http://brasil.ipni.net/beagle/BRS-3137\&f=Encarte103.pdf. Acesso em: 12 nov. 2017.

RODRIGUES, C. M. Evaporação e evapotranspiração. In: SHAIDIAN, S.; GUIMARÃES, C. R.; RODRIGUES, C. M. (org.). Hidrologia agrícola. Évora: Universidade de Évora, 2017. v. 1, p. 215-234.

SANTOS, W. O.; SOBRINHO, J. E.; MEDEIROS, J. F.; MOURA, M. S. B.; NUNES, R. L. C. Coeficientes de cultivo e necessidades hídricas da cultura do milho verde nas condições do semiárido brasileiro. Irriga, Botucatu, v. 19, n. 4, p.559-572, 2014. Disponível em: https://doi.org/10.15809/irriga.2014v19n4p559. Acesso em: 05 nov. 2017.

SCHLESINGER, W. H.; JASECHKO, S. Transpiration in the global water cycle. Agricultural and Forest Meteorology, Amsterdam, v. 189-190, n. 1, p.115-117, 2014. Disponível em: https://doi.org/10.1016/j.agrformet.2014.01.011. Acesso em: 15 nov. 2017.

SILVA, E. M. P.; ANDRADE JUNIOR, A. S.; BASTOS, E. A.; VIANA, T. V. A. Evapotranspiração e coeficiente de cultura da melancia em solo sob palhada e preparo convencional. Irriga, Botucatu, v. 20, n. 1, p.154-164, 2015a. Disponível em: https://doi.org/10.15809/irriga.2015v20n1p165. Acesso em: 15 mai. 2019.

SILVA, L. D.; LIMA, R., SANTOS, R. F.; BORSOI, A. Estimativa de evapotranspiração de referência para o município de Palotina-PR. Acta Iguazu, Cascavel, v. 4, n. 4, p.89-100, 2015b. Disponível em: http://e-revista.unioeste.br/index.php/actaiguazu/article/view/14503. 10 abr. 2019.

SILVA, M. R.; VANZELA, L. S.; VAZQUEZ, G. H.; SANCHES, A. C. Influência da irrigação e cobertura morta do solo sobre as características agronômicas e produtividade de milho. Irriga, Botucatu, v. 1, n. 1, p.170-180, 2012. Disponível em: https://doi.org/10.15809/irriga.2012v1n01p170. Acesso em: 15 nov. 2017.

SOUZA, L. S. B.; MOURA, M. S. B.; SEDIYAMA, G. C.; SILVA, T. G. F. Requerimento hídrico e coeficiente de cultura do milho e feijão-caupi em sistemas exclusivo e consorciado. Revista Caatinga, Mossoró, v. 28, n. 4, p.151-160, 2015. Disponível em: http://dx.doi.org/10.1590/1983-21252015v28n417rc. Acesso em: 22 nov. 2017. 